\title{
DESENVOLVIMENTO E PRODUTIVIDADE DE ARROZ IRRIGADO EM RESPOSTA A DIFERENTES DOSES DE FÓSFORO E POTÁSSIO, EM VÁRZEA DE PRIMEIRO ANO, NO ESTADO DE RORAIMA
}

\author{
Growth and productivity of irrigated rice in response to diferent doses of \\ phosphorus and potassium in lowland soil of first year in the state of Roraima
}

\author{
Diego da Silva Barberena', Roberto Dantas de Medeiros², Gilvan Ferreira Barbosa²
}

\begin{abstract}
RESUMO
São poucas as pesquisas em Roraima sobre o uso de fósforo e potássio na cultura do arroz irrigado (Oryza sativa L.). Assim, neste trabalho, objetivou-se avaliar a resposta do arroz irrigado à aplicação de diferentes doses de fósforo e potássio $(0,50,100,200$ e $400 \mathrm{~kg} \mathrm{ha}^{-1}$ de $\mathrm{P}_{2} \mathrm{O}_{5}$ ou $\mathrm{K}_{2} \mathrm{O}$ ) sobre a produtividade de grãos, altura de plantas e componentes de produção em área de primeiro ano de cultivo. Utilizou-se o delineamento em blocos aos acaso, no esquema de parcelas subdivididas com quatro repetições. Foi feita análise de regressão, por meio da superfície de resposta. O potássio influenciou significativa e positivamente todas as variáveis, exceto a massa de mil grãos, reduzindo-a linearmente, sendo seu efeito o principal responsável pelas produtividades alcançadas. O fósforo influenciou positivamente a massa de mil grãos e a produtividade de grãos. O número de grãos por panícula, a massa de mil grãos e a altura de plantas contribuíram decisivamente para as produtividades atingidas. A maior produtividade encontrada $\left(8.154 \mathrm{~kg} \mathrm{ha}^{-1} \mathrm{de}\right.$ grãos) ocorreu com uso de $304 \mathrm{~kg} \mathrm{ha}^{-1}$ de $\mathrm{P}_{2} \mathrm{O}_{5}$ e $228 \mathrm{~kg} \mathrm{ha}^{-1}$ de $\mathrm{K}_{2} \mathrm{O}$. A máxima eficiência econômica foi obtida com $134 \mathrm{e} 158 \mathrm{~kg} \mathrm{ha}^{-1} \mathrm{de}$ $\mathrm{P}_{2} \mathrm{O}_{5}$ e K 2 , respectivamente, e produtividade de $7.501 \mathrm{~kg} \mathrm{ha}^{-1}$ de grãos, proporcionando lucro líquido de $\mathrm{R} \$ 696,78$ ha $^{-1}$, relação benefício/custo de 1,18 e custo unitário de $\mathrm{R} \$ 0,5271 \mathrm{~kg}^{-1}$ de arroz.
\end{abstract}

Termos para indexação: Oryza sativa L., correção da fertilidade, análise econômica.

\begin{abstract}
There are few studies about the use of phosphorus and potassium in irrigated rice (Oryza sativa L.) in the State of Roraima. The objetive of this study was to evaluate the response of rice to the application of different doses of phosphorus and potassium ( 0 , $50,100,200$ and $400 \mathrm{~kg} \mathrm{ha}^{-1} \mathrm{P}_{2} \mathrm{O}_{5} \mathrm{~K}_{2} \mathrm{O}$ ) on productivity, plant height and yield composition in an area in the first year of cultivation. A randomized blocks design was used in a split plot with four replicates. A regression analysis was PERFORMED using surface response. The potassium significantly and positively affected all variables except weight of thousand grains, reducing it linearly. wits its effect being the responsible for the achieved productivity. The phosphorus positively influenced the weight of thousand grains and productivity. The number of grains per panicle, the weight of thousand grains and plant height contributed decisively to the yields achieved. The higher productivity found $\left(8,154 \mathrm{~kg} \mathrm{ha}^{-1}\right.$ grains) occurred with the use of $304 \mathrm{~kg} \mathrm{ha}^{-1} \mathrm{P}_{2} \mathrm{O}_{5}$ and $228 \mathrm{~kg} \mathrm{ha}^{-1} \mathrm{~K}_{2} \mathrm{O}$. The maximum economic efficiency was obtained with 134 and $158 \mathrm{~kg} \mathrm{ha}^{-1} \mathrm{P}_{2} \mathrm{O}_{5}$ and $\mathrm{K}_{2} \mathrm{O}$, respectively, and yield of 7,501 kg ha $\mathrm{grain}^{-1}$, providing net earnings of $\mathrm{R} \$ 696.78 \mathrm{ha}^{-1}$, benefit / cost ratio of 1.18 and unit cost of $\mathrm{R} \$ 0.5271 \mathrm{~kg}^{-1} \mathrm{rice}$.
\end{abstract}

Index terms: Oryza sativa L., correction of fertility, economic analysis.

(Recebido em 15 de junho de 2009 e aprovado em 10 de maio de 2010)

\section{INTRODUÇÃO}

O arroz (Oriyza sativa L.) é um dos cereais de maior importância social e econômica para o mundo, sendo responsável pela alimentação de dois terços da população mundial, fornecendo aproximadamente $20 \%$ de energia e $15 \%$ da proteína necessária ao ser humano.

No Brasil, o arroz é cultivado em todo o país, sendo o irrigado responsável por mais da metade da produção nacional., Em Roraima, o arroz irrigado é a principal cultura agrícola, ocupando na safra 2007/08 cerca de 24.000 hectares, com produção de 152.400 toneladas de arroz em casca, com produtividade média de $6.350 \mathrm{~kg} \mathrm{ha}^{-1}$ de grãos (Fecomércio, 2008).

Entretanto, em razão da baixa fertilidade dos solos do estado, onde o nitrogênio e o fósforo são limitantes para a cultura em área de primeiro ano de cultivo (Medeiros et al., 2004), para se obter esta produtividade são necessárias o uso de altas doses de fertilizantes químicos. E, por não existirem resultados de pesquisas local sobre a correção adequada da fertilidade e sua manutenção nos cultivos sucessivos, os produtores utilizam, indiscriminadamente, em torno de $150 \mathrm{~kg} \mathrm{ha}^{-1}$ de fósforo e

\footnotetext{
IUniversidade federal de Roraima/UFRR - Avenida Ene Garces - 2413 - Bairro Aeroporto - Boa Vista, RR - dibarberena@yahoo.com Universidade federal de Roraima/UFRR - Avenida Ene Garces - 2413 - Bairro Aeropo
'Empresa Brasileira de Pesquisa Agropecuária/EMBRAPA/CPAFRR - Boa Vista, RR
} 
de potássio, respectivamente. Isso corresponde à aplicação em torno de $600 \mathrm{~kg} \mathrm{ha}^{-1}$ de fórmulas como 10-26-26 e/ou 0525-25 + Zn, independentemente se a área é de primeiro ano de cultivo e/ou já trabalhada há diversos anos, onerado significativamente os custos de produção, pois representa cerca de $30 \%$ do custo total da lavoura (Banco da Amazônia, 2006).

Em Roraima, há em torno de 160.000 ha de várzeas com potencial para a exploração com arroz irrigado. $\mathrm{O}$ comportamento da cultura nessas várzeas é muito influenciado por seu manejo, visto que são tipos de solos com características químicas e físico-hídricas distintas. Para tanto, é necessário desenvolver-se sistemas de manejo de adubação adequados a cada situação específica (Santos et al., 1999), capaz de proporcionar produtividade de grãos técnica e economicamente viáveis (Fageria et al., 2000).

A cultura do arroz irrigado responde à aplicação de nitrogênio (Hernandes et al., 2010) bem como potássio e fósforo, aumentado a produtividade de grãos (Carvalho Júnior, 1987; Fageria et al., 2000). Entretanto, a resposta desses nutrientes na cultura é influenciada pelas características físicoquímicas do solo e pelo manejo os quais são determinantes na disponibilidade desses elementos às plantas (Fageria \& Zimmermmann, 1996).

Para tanto, neste trabalho, objetivou-se testar diferentes doses de fósforo e de potássio na cultura do arroz irrigado em várzeas de primeiro ano de cultivo e avaliar os efeitos dessas doses sobre altura de plantas, os componentes de produção e produtividade de grãos de arroz.

\section{MATERIAL E MÉTODOS}

O estudo foi realizado em área de produção tradicional de arroz irrigado no município do Bonfim, no estado de Roraima, na Fazenda Paraíso, a 96 km de Boa
Vista, com sede localizada na latitude $3^{\circ} 19^{\prime} 3^{\prime \prime}$ Norte e longitude $60^{\circ} 20^{\prime} 38^{\prime \prime}$ Oeste, em área de solo classificado como Gleissolo Aplico Tb Distrófico no ano agrícola 2007/08.

$\mathrm{O}$ ensaio foi instalado em área de primeiro ano de cultivo sem histórico de adubações anteriores ou cultivo com outros vegetais a não ser pastagem nativa. A análise química do solo pré-implantação do experimento buscou coletar informações nas profundidades de $0-15 \mathrm{~cm}$ e 15 a $30 \mathrm{~cm}$. Essas coletas revelaram as seguintes características químicas e físicas (Tabela 1):

Os tratamentos constaram de cinco doses de fósforo $\left(0,50,100,200\right.$ e $400 \mathrm{~kg} \mathrm{ha}^{-1}$ de $\left.\mathrm{P}_{2} \mathrm{O}_{5}\right)$ combinados com cinco doses de Potássio $\left(0,50,100,200,400 \mathrm{~kg} \mathrm{ha}^{-1} \mathrm{de}\right.$ $\mathrm{K}_{2} \mathrm{O}$ ), respectivamente, resultando em 25 tratamentos.

Utilizou-se o delineamento experimental de blocos ao acaso no esquema de parcelas subdivididas com quatro repetições. As parcelas principais com área de $120 \mathrm{~m}^{2}(6 \mathrm{x}$ $20 \mathrm{~m}$ ) foram constituídas pelos níveis de potássio e nas subparcelas com área de $12 \mathrm{~m}^{2}(3 \mathrm{~m} \mathrm{x} 4 \mathrm{~m})$ foram casualizadas as doses de fósforo, cuja área útil foi de 7,5 $\mathrm{m}^{2}$ ( $3 \times 2,5 \mathrm{~m})$. Cada parcela com as doses de potássio foi separada por uma taipa, para a qual foram deixados $2 \mathrm{~m}$ de espaçamento, evitando a contaminação dos tratamentos adjacentes após a formação da lâmina de água.

Utilizou-se a cultivar de arroz irrigado BR Roraima, semeada a lanço, na densidade de $160 \mathrm{~kg}$ de sementes $\mathrm{ha}^{-1}$. A adubação de semeadura constou de $24 \mathrm{~kg} \mathrm{ha}^{-1}$ de nitrogênio, aplicado na forma de uréia $+50 \mathrm{~kg} \mathrm{ha}^{-1}$ de FTE BR 12 e as doses de fósforo e potássio estabelecidas como tratamentos. Em cobertura, utilizou-se $200 \mathrm{~kg} \mathrm{ha}^{-1}$ de uréia, divididos em duas aplicações, efetuadas aos 18 e aos 45 dias após a emergência das plântulas.

O sistema de irrigação foi por inundação continua, com lâmina de água de 5 a $15 \mathrm{~cm}$ de profundidade, iniciada

Tabela 1 - Características químicas e físicas do solo de várzea em primeiro ano de cultivo, utilizado no experimento.

\begin{tabular}{|c|c|c|c|c|c|c|c|c|c|c|c|c|}
\hline \multicolumn{13}{|c|}{ Características químicas } \\
\hline Prof. & $\mathrm{pH}$ & $\mathrm{Ca}$ & $\mathrm{Mg}$ & $\mathrm{K}$ & $\mathrm{Al}$ & $\mathrm{H}+\mathrm{Al}$ & SB & CTCt & CTCe & $\mathrm{P}$ & $\mathrm{V}$ & $\mathrm{m}$ \\
\hline $\mathrm{cm}$ & \multicolumn{9}{|c|}{ - } & \multicolumn{3}{|c|}{------mg/dm³---\%--- } \\
\hline $0-15$ & 5,2 & 0,97 & 0,23 & 0,17 & 1,01 & 4,62 & 1,37 & 6,0 & 2,4 & 2,54 & 22,9 & 42 \\
\hline $15-30$ & 5,3 & 0,91 & 0,19 & 0,14 & 2,66 & 6,02 & 1,24 & 7,3 & 3,9 & 1,48 & 17,1 & 68 \\
\hline \multicolumn{10}{|c|}{ Composição Granulométrica (\%) } & \multicolumn{3}{|c|}{ MO } \\
\hline & & Areia & & \multicolumn{3}{|c|}{ Silte } & \multicolumn{3}{|c|}{ Argila } & \multicolumn{3}{|c|}{$\mathrm{g} / \mathrm{kg}$} \\
\hline $0-15$ & & 13 & & \multicolumn{3}{|c|}{54} & \multicolumn{3}{|c|}{33} & \multicolumn{3}{|c|}{20,5} \\
\hline $15-30$ & & 8 & & \multicolumn{3}{|c|}{38} & \multicolumn{3}{|c|}{54} & \multicolumn{3}{|c|}{9,1} \\
\hline
\end{tabular}

1.pH = ph em água; $\mathrm{Ca} ; \mathrm{Mg} ; \mathrm{K} ; \mathrm{Al} ; \mathrm{H}+\mathrm{Al} ; \mathrm{SB}=$ soma de bases; $\mathrm{CTCt}=$ capacidade de troca de cátions total; $\mathrm{CTCe}=$ capacidade de troca de cátions efetiva; $\mathrm{V}=$ saturação por bases; $\mathrm{m}$ = saturação por alumínio trocável. 
a partir dos 15 dias após a emergência das plântulas de arroz. O controle de plantas daninhas foi feito utilizandose a mistura de propanil + 2,4-D (nas doses de 6,0 e 0,2 L de ingrediente ativo $\mathrm{ha}^{-1}$, respectivamente).

Foram avaliados na área útil de cada parcela a altura de plantas, determinada em 10 plantas por parcela, o número de panículas, determinado em quatro subamostras de $0,25 \mathrm{~m}^{2}$, o numero de grãos total, cheios e estéreis, por panícula, obtidos em dez panículas colhidas por parcela, a massa de mil grãos, determinada conforme as regras de analise de sementes (Brasil, 1992) e a produtividade de grãos, com peso corrigido para $13 \%$ de umidade conforme Machado et al. (2006).

A analise econômica foi obtida por meio da derivação da equação de regressão para produtividade considerando-se o preço para a saca de arroz em casca como $\mathrm{R} \$ 31,00$ e valor do $\mathrm{kg}$ de $\mathrm{P}_{2} \mathrm{O}_{5}$ como $\mathrm{R} \$ 3,48$ e $\mathrm{K}_{2} \mathrm{O} \mathrm{R} \$ 3,08$, obtidos a partir da divisão do preço da tonelada de Cloreto de Potássio e Superfosfato triplo pelos teores desses nutrientes nessas fontes, sendo calculada a relação insumo/ produto e igualada as derivadas $\mathrm{dy} / \mathrm{dP}$ e $\mathrm{dy} / \mathrm{dK}$, obtendose por isolamento a relação insumo/produto.

Os dados foram analisados por meio da análise de variância com aplicação do teste $\mathrm{F}(\mathrm{p}<0,05)$, sendo testado o modelo de regressão múltipla de superfície de resposta $\hat{\mathrm{Y}}=\mathrm{bo}+\mathrm{b}_{1} \mathrm{X}+\mathrm{b}_{2} \mathrm{X}^{2}+\mathrm{b}_{3} \mathrm{Z}+\mathrm{b}_{4} \mathrm{Z}^{2}+\mathrm{b}_{5} \mathrm{XZ}$, onde o é o valor da variável dependente em estudo, bo é média obtida na variável dependente estudada, $b_{1,2,3,4 \mathrm{e} 5}$ são os coeficientes dos componentes lineares, quadráticos e da interação dos fatores em estudo (X e Z) testados. X é o teor de fósforo aplicado $\left(\mathrm{kg} \mathrm{ha}^{-1}\right.$ de $\left.\mathrm{P}_{2} \mathrm{O}_{5}\right)$ e $\mathrm{Z}$ é o teor de potássio aplicado $\left(\mathrm{kg} \mathrm{ha}^{-1}\right.$ de $\left.\mathrm{K}_{2} \mathrm{O}\right)$. Também se fez a correlação entre a produtividade obtida, seus componentes de produção e a altura de planta. Foi utilizado o software SAEG 9.1 (Reis, 2001) para o processamento das análises.

\section{RESULTADOS E DISCUSSÃO}

Nas variáveis número de grãos cheios, altura de plantas e número total de grãos houve efeito principal significativo apenas das doses de potássio, em seus efeitos lineares e quadráticos (Tabela 2 e Figura 1b, c, d ).

O máximo de grãos cheios obtidos $(107,49$ grãos por panícula) foi alcançado na dose de $212,95 \mathrm{~kg} \mathrm{ha}^{-1}$; já, a altura de plantas máxima alcançada $(106,51 \mathrm{~cm})$ foi obtida com de 230,34 $\mathrm{kg} \mathrm{ha}^{-1}$; enquanto o maior número total de grãos $(123,41$ grãos por panícula) foi obtido com $227,11 \mathrm{~kg} \mathrm{ha}^{-1}$ de $\mathrm{K}_{2} \mathrm{O}$.

Não houve efeito principal significativo sobre a massa de mil grãos para os fatores estudados, entretanto, foram significativos os componentes lineares do efeito de potássio e o componente quadrático do efeito de fósforo na superfície de resposta testada (Tabela 2, Figura 2). Segundo Gomes (1987), na análise de variância é pressuposto a independência entre os tratamentos utilizados e isso não se verifica no estudo de fatores quantitativos, onde a dependência entre os tratamentos é um fato bem estabelecido. Nesse caso, os efeitos associados à regressão devem ser considerados acima dos resultados apresentados pelo efeito principal da análise de variância sob pena dessa análise não ser válida. Assim, conclui-se que a massa de mil grãos foi reduzida linearmente pela aplicação do potássio, mas que cresceu de forma quadrática em resposta ao uso do fósforo (Figura 2), com valor máximo de 28, $21 \mathrm{~g} \mathrm{mil}^{-1}$ sementes na dose de 178,62 $\mathrm{kg} \mathrm{ha}^{-1}$ de $\mathrm{P}_{2} \mathrm{O}_{5}$ e zero de potássio. Esse fato esta relacionado com o aumento do tamanho da panícula, como se verá mais adiante. A média geral ficou em $25,77 \mathrm{~g} \mathrm{mil}^{-1}$ grãos sendo esse resultado ideal para a cultura do arroz (Costa et al., 2000), concordando com os dados encontrados por Fageria et al. (2000) em estudos com diferentes níveis de P e $\mathrm{K}$, onde obtiveram resultados semelhantes para esta variável em seu experimento com três anos de cultivo consecutivos.

A altura de plantas na dose $200 \mathrm{~kg} \mathrm{ha}^{-1}$ de $\mathrm{K}_{2} \mathrm{O}$ alcançou a média de $104,71 \mathrm{~cm}$, não se diferenciando da dose média $100 \mathrm{~kg} \mathrm{ha}^{-1}$ (Tabela 2). Essa dose não se diferenciou da que propiciou a maior produtividade (228 $\mathrm{kg} \mathrm{ha}^{-1}$ de $\mathrm{K}_{2} \mathrm{O}$ ), evidenciando a estreita relação de dose para a melhor resposta ao nutriente para as duas variáveis nas condições do experimento. Fageria \& Zimmermmann (1996), testando diferentes níveis de combinados de $\mathrm{K}_{2} \mathrm{O}$ e $\mathrm{P}_{2} \mathrm{O}_{5}$ com 50 a 200 e 40 a $160 \mathrm{~kg} \mathrm{ha}^{-1}$ respectivamente, em casa de vegetação para várias cultivares, obtiveram altura média de 76 a $89 \mathrm{~cm}$, ficando estas um pouco abaixo da média do experimento, a qual foi $96 \mathrm{~cm}$.

Houve efeito principal significativo de potássio e sua interação com fósforo no número de grão estéreis por panícula. Porém, não houve ajuste significativo da superfície de resposta estudada, indicando ser complexa o efeito desses nutrientes sobre essa variável. Em geral, houve uma tendência de aumento na esterilidade com o incremento de potássio e redução na esterilidade com o aumento de fósforo (Tabela 2).

Para o número de panículas por metro quadrado houve efeito principal de potássio e de fósforo, assim como sua interação (Tabela 2). Porém, não houve ajuste significativo para os efeitos lineares e quadrático do fósforo, sendo essa variável explicada pelos efeitos lineares e quadráticos do potássio, em interação linear com o fósforo. O melhor resultado obtido para a variável ocorreu 
nas doses $400 \mathrm{~kg} \mathrm{ha}^{-1}$ de $\mathrm{K}_{2} \mathrm{O}$ e $\mathrm{P}_{2} \mathrm{O}_{5}$ com 470 panículas por $\mathrm{m}^{2}$. No entanto, nesses níveis, a altura de plantas, número de grãos por panícula e massa de mil grãos, que se relacionaram mais significativamente com a produtividade, apresentaram menor respostas aos nutrientes.

O número de panículas na máxima produtividade obtida ficou em 366,25 , ficando a média geral do experimento em 395,26 panículas $/ \mathrm{m}^{2}$ (Figura 1a) discordando de Santos et al. (1999), testando diferentes manejos da lâmina de água e doses de $\mathrm{K}_{2} \mathrm{O}$ obtiveram valores de 533 a 655 panículas $\mathrm{m}^{-2}$, sendo as melhores médias obtidos para o manejo com irrigação continua e parcelamento de $70 \mathrm{~kg} \mathrm{ha}^{-1}$ do nutriente. Vale ressaltar que apesar do número bem maior obtido para a variável na pesquisa citada, o número de grãos por panícula foi menor que o obtido nesta pesquisa, não levando a maior produtividade que a obtida no experimento aqui estudado.

A dose de $231,25 \mathrm{~kg} \mathrm{ha}^{-1}$ de $\mathrm{K}_{2} \mathrm{O}$ apresentou o menor valor para panículas por $\mathrm{m}^{2}$ (Figura 3 ) quando em combinação com qualquer dose de $\mathrm{P}_{2} \mathrm{O}_{5}$. Essa dose propiciou o melhor resultado, quando em combinação com $400 \mathrm{~kg} \mathrm{ha}^{-1}$ de $\mathrm{P}_{2} \mathrm{O}_{5}$, obtendo-se 382,38 panículas.

Para a produtividade, por sua vez, houve efeito principal de potássio e fósforo, porém no ajuste da superfície de resposta houve também interação entre esses fatores. Os efeitos lineares e quadráticos, assim com a

Tabela 2 - Resposta de produtividade e componentes de rendimento de arroz irrigado a diferentes níveis de $\mathrm{P}_{2} \mathrm{O}_{5} *$ e $\mathrm{K}_{2} \mathrm{O}$.

\begin{tabular}{|c|c|c|c|c|c|c|c|}
\hline $\begin{array}{c}\text { Doses e Fontes } \\
\text { usadas }\end{array}$ & $\begin{array}{l}\text { Massa } \\
\text { mil } \\
\text { grãos } \\
(\mathrm{g})\end{array}$ & $\begin{array}{c}\mathrm{N}^{\circ} \text { de grãos } \\
\text { cheios/ } \\
\text { panícula }\end{array}$ & $\begin{array}{c}\text { No de grãos } \\
\text { estéreis/ } \\
\text { panícula }\end{array}$ & $\begin{array}{l}\text { Altura } \\
\text { de } \\
\text { plantas } \\
(\mathrm{cm})\end{array}$ & $\begin{array}{l}\text { Panículas } \\
\left(\mathrm{m}^{2}\right)\end{array}$ & $\begin{array}{l}\text { Total de } \\
\text { grãos/ } \\
\text { panícula }\end{array}$ & $\begin{array}{l}\text { Produtividade } \\
\qquad\left(\mathrm{kg} \mathrm{ha}^{-1}\right)\end{array}$ \\
\hline $\mathrm{kg} \mathrm{ha}^{-1} \mathrm{P}_{2} \mathrm{O}_{5}$ & \multicolumn{7}{|c|}{ - } \\
\hline 0 & 24,47 & 80,76 & 18,06 & 91,81 & 358,80 & 98,82 & 5287 \\
\hline 50 & 26,20 & 88,20 & 16,91 & 93,64 & 409,40 & 105,11 & 6228 \\
\hline 100 & 27,71 & 86,78 & 15,21 & 97,14 & 396,80 & 101,98 & 6488 \\
\hline 200 & 26,33 & 86,82 & 15,38 & 93,38 & 387,70 & 102,20 & 6650 \\
\hline 400 & 23,90 & 84,05 & 14,93 & 95,34 & 423,60 & 98,98 & 6814 \\
\hline $\mathrm{kg} \mathrm{ha}^{-1} \mathrm{~K}_{2} \mathrm{O}$ & \multicolumn{7}{|c|}{ 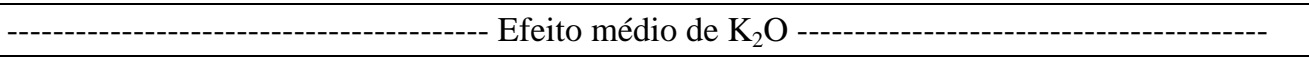 } \\
\hline 0 & 27,80 & 63,82 & 14,15 & 81,23 & 425,7 & 77,97 & 4819 \\
\hline 50 & 26,70 & 84,33 & 14,56 & 92,06 & 465,6 & 98,88 & 6808 \\
\hline 100 & 25,45 & 98,69 & 13,54 & 100,11 & 339 & 112,23 & 6934 \\
\hline 200 & 23,74 & 104,44 & 15,54 & 104,71 & 345,6 & 119,98 & 6641 \\
\hline 400 & 24,93 & 75,33 & 22,71 & 93,20 & 400,4 & 98,04 & 5947 \\
\hline Teste F (K) & (ns) & $(0,00 * *)$ & $(0,00 * *)$ & $\left(0,00^{* *}\right)$ & $(0,00 * *)$ & $(0,00 * *)$ & $(0,00 * *)$ \\
\hline Ef. Linear ${ }^{(1)}$ & $*$ & $0,00 * * *$ & $0,38^{\mathrm{ns}}$ & $0,00^{* * *}$ & $0,00 * * *$ & $0,00 * * *$ & $0,00 * * *$ \\
\hline Ef. Quadrático ${ }^{(2)}$ & ns & $0,00 * * *$ & $0,09^{\mathrm{ns}}$ & $0,00^{* * * *}$ & $0,00 * * *$ & $0,00 * * *$ & $0,00 * * *$ \\
\hline Teste F (P) & (ns) & (ns) & (ns) & (ns) & $(0,02 *)$ & (ns) & $(0,00 * *)$ \\
\hline Ef. Linear ${ }^{(1)}$ & $\mathrm{ns}$ & $0,19^{\mathrm{ns}}$ & $0,06^{\mathrm{ns}}$ & $0,23^{\mathrm{ns}}$ & $0,99^{\mathrm{ns}}$ & $0,97^{\mathrm{ns}}$ & $0,00 * * *$ \\
\hline Ef. Quadrático ${ }^{(2)}$ & $*$ & $0,18^{\mathrm{ns}}$ & $>0,99^{\mathrm{ns}}$ & $>0,99^{\mathrm{ns}}$ & $>0,99^{\mathrm{ns}}$ & $>0,99^{\mathrm{ns}}$ & $0,00 * * *$ \\
\hline Teste F (K x P) & (ns) & (ns) & $(0,03 * *)$ & (ns) & $(0,02 *)$ & (ns) & (ns) \\
\hline Efeito XZ ${ }^{(3)}$ & $\mathrm{ns}$ & ns & $0,17^{\mathrm{ns}}$ & $>0,99^{\mathrm{ns}}$ & $0,03^{*}$ & $>0,99^{\mathrm{ns}}$ & $0,00 * *$ \\
\hline C.V (a), \% & 33,04 & 17,44 & 47,76 & 6,38 & 15,27 & 17,59 & 9,64 \\
\hline C.V. (b), \% & 20,25 & 22,06 & 44,69 & 7,54 & 16,14 & 22,55 & 8,35 \\
\hline
\end{tabular}

*,**, ns = significativo a 5\%, $1 \%$ e não significativo, respectivamente, pelo teste F; CV (a) e (b), coeficientes de variação da parcela e subparcela, respectivamente. ${ }^{(1)},{ }^{(2)} \mathrm{e}^{(\mathrm{XZ})}$ componentes linear, quadrático e interação dos fatores em estudo na superficie de resposta testada. 
interação, foram altamente significativos. A máxima produtividade física obtida no experimento ocorreu nas doses de $304,20 \mathrm{~kg} \mathrm{ha}^{-1} \mathrm{P}_{2} \mathrm{O}_{5}$ e $228 \mathrm{~kg} \mathrm{ha}^{-1}$ de $\mathrm{K}_{2} \mathrm{O}$, com obtenção de $8.154 \mathrm{~kg} \mathrm{ha}^{-1}$ de grãos em casca, estimada pela equação de regressão (Figura 4). O teor disponível de fósforo no solo era muito baixo, porém o de potássio era de média a adequado no solo trabalhado de acordo com análise de solo. A alta dose necessária para adubação no primeiro ano de cultivo era esperada para fósforo, em razão do baixo teor disponível e ao teor de argila ( $33 \mathrm{dag} \mathrm{kg}^{-1}$ ) na camada de 0 a $15 \mathrm{~cm}$, e 54 dag kg-1 na camada de 15 a $30 \mathrm{~cm}$. Segundo Sousa \& Lobato (2004), são necessários a aplicação de 150 a $300 \mathrm{~kg} \mathrm{ha}^{-1}$ de $\mathrm{P}_{2} \mathrm{O}_{5}$ na correção da fertilidade em solos com teores de $\mathrm{P}$ muito baixo e teores de argila, variando de 16 a 35 e 36 a 60 dag kg-1, respectivamente. Além disso, é necessário um adicional em manutenção de 80 a $120 \mathrm{~kg} \mathrm{ha}^{-1}$ para alcançar as maiores produtividade a partir do primeiro ano. Esses valores totais ( 230 a $420 \mathrm{~kg} \mathrm{ha}^{-1}$ ) são compatíveis com o observado neste trabalho, em se tratando da plena correção da fertilidade do solo já no primeiro ano. Entretanto, se o objetivo for ter o máximo retorno econômico já no primeiro ano, as doses de 134,32 $\mathrm{kg} \mathrm{ha}^{-1}$ de $\mathrm{P}_{2} \mathrm{O}_{5}$ e $157,92 \mathrm{~kg} \mathrm{ha}^{-1}$ de $\mathrm{K}_{2} \mathrm{O}$ permitem o alcance de produtividade média de $7.501 \mathrm{~kg} \mathrm{ha}^{-1}$, com rentabilidade de $\mathrm{R} \$ 696,78 \mathrm{ha}^{-1}$ e seriam as doses mais indicadas.

Resposta em produção ao uso de fósforo no arroz em cultivo de solos de várzeas irrigados por inundação é comum no Brasil. Mariano et al. (2002), testando doses crescentes de 75 a $800 \mathrm{mg} \mathrm{dm}^{-3}$ de $\mathrm{P}$, encontraram resposta positiva até $519 \mathrm{mg} \mathrm{dm}^{-3}$, com calagem, e $623 \mathrm{mg} \mathrm{dm}^{-3}$, sem calagem, em casa de vegetação. Genro Junior et al. (2010) avaliando a eficácia das recomendações de adubação para diferentes expectativas de produtividade em diferentes solos encontraram respostas crescentes as doses do nutriente, variando-o de 0 a $85 \mathrm{~kg} \mathrm{ha}^{-1}$, obtiveram produtividades de 3,2 a 12 toneladas ha- ${ }^{-1}$, sendo os valores máximos alcançados com dose média de $60 \mathrm{~kg} \mathrm{ha}^{-1}$. Já Rotili et al. (2010) testando a eficiência no uso de fósforo em oito cultivares, utilizando 20 e $120 \mathrm{~kg} \mathrm{ha}^{-1}$ observaram eficiência no uso e resposta a sua aplicação em apenas uma cultivar.

$\mathrm{O}$ alto requerimento em potássio, já no primeiro ano e em solo com teor superior a $66 \mathrm{mg} \mathrm{dm}^{-3}$ de $\mathrm{K}$ disponível encontrado na análise de solo, é surpreendente, pois nas demais regiões produtoras de arroz esse nível de potássio é considerado adequado e raramente se recomenda mais
A

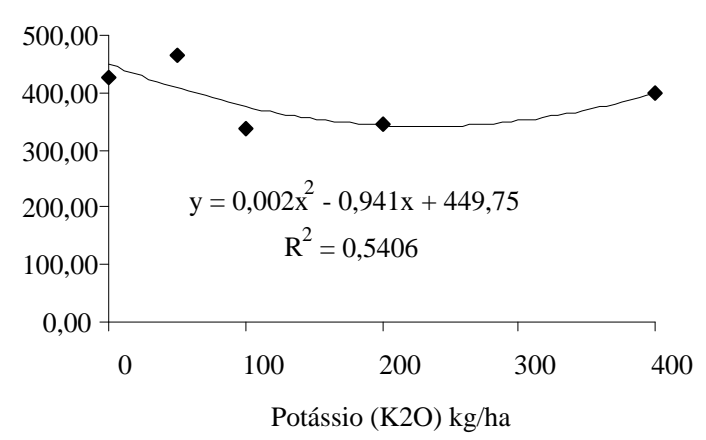

C

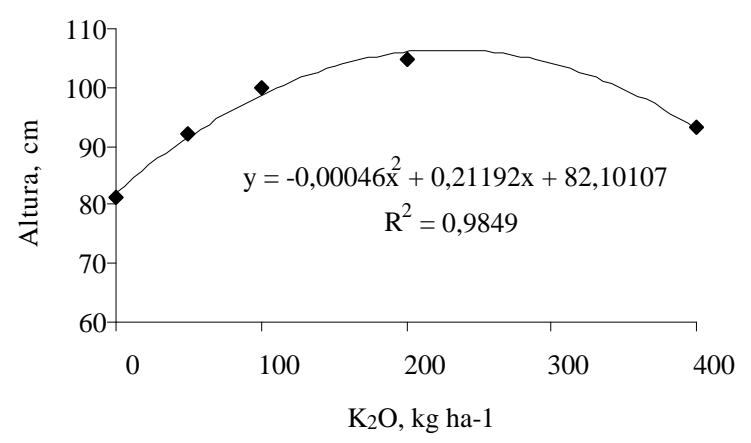

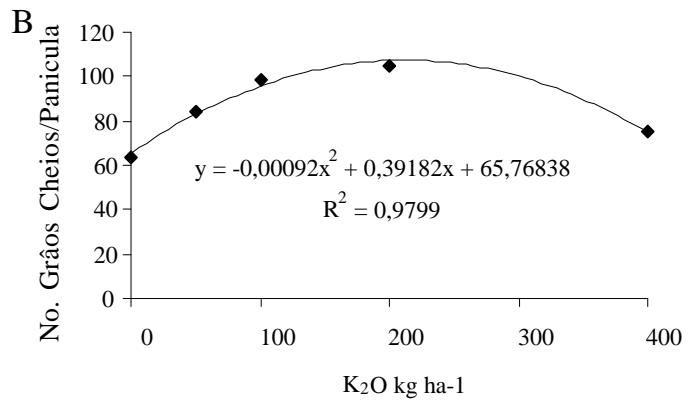

$\mathrm{D}$

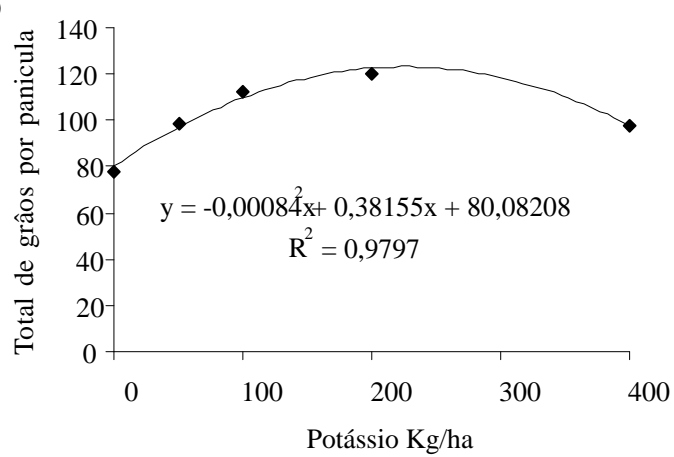

Figura 1 - Panículas m² (A), grãos cheios por panícula (B), altura (C) e total de grãos por panícula (D) em função de doses de potássio na cultivar BR Roraima, em várzea do estado de Roraima, safra 2007/08. 
que $90 \mathrm{~kg} \mathrm{ha}^{-1}$ de $\mathrm{K}_{2} \mathrm{O}$. Possivelmente, a alta produtividade alcançada no primeiro ano (8.154 $\mathrm{kg} \mathrm{ha}^{-1}$ ) (Tabela 3$)$, a interação com o fósforo e outras razões associadas ao manejo da cultura, especialmente a irrigação, possam explicar esse resultado. Segundo Diel et al. (2007) o potássio pode ser dissolvido na água de irrigação e ser transportado para as áreas vizinhas, onde pode contribuir para a nutrição dos cultivos vizinhos, em áreas de várzeas. Esse deslocamento do potássio na água de irrigação, em várzeas inundadas, também foi encontrado por Marchezan et al. (2001), Weber et al. (2003) e Machado et al. (2006). Assim, parte do potássio aplicado em área total no início do experimento pode ter sido deslocado pela água de irrigação. Entretanto, a dose de máxima eficiência econômica de

$$
\mathrm{Y}=0,00259911+0,0248541 * \mathrm{P}-0,695637 \mathrm{P}^{2}-0,693975 \mathrm{~K}
$$
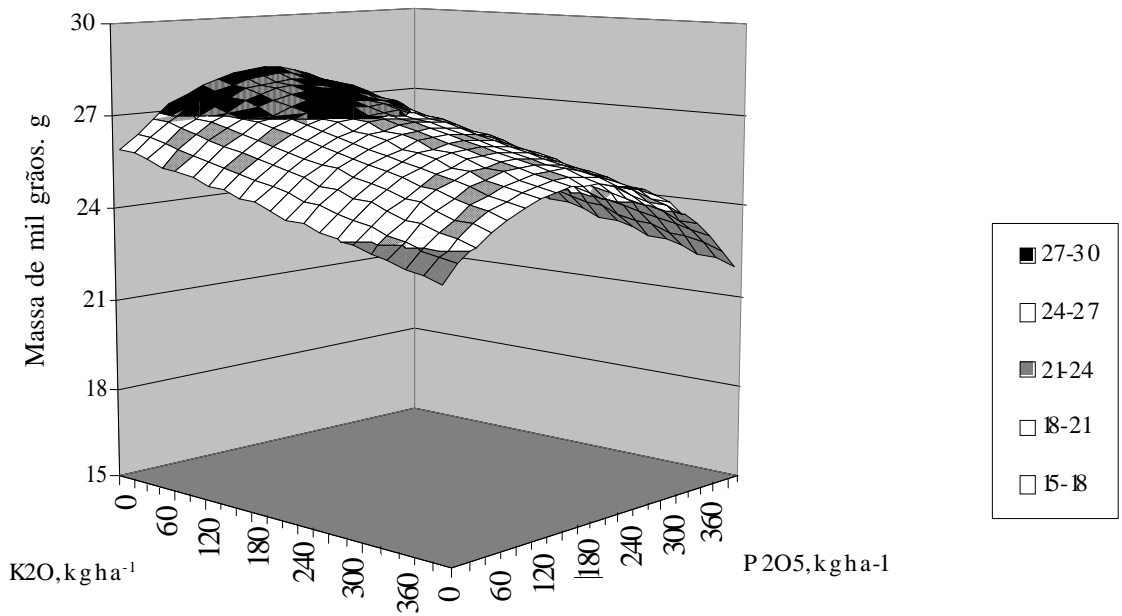

Figura 2 - Massa de mil grãos em função de doses de potássio e fósforo na cultivar BR Roraima, safra 2007/08.

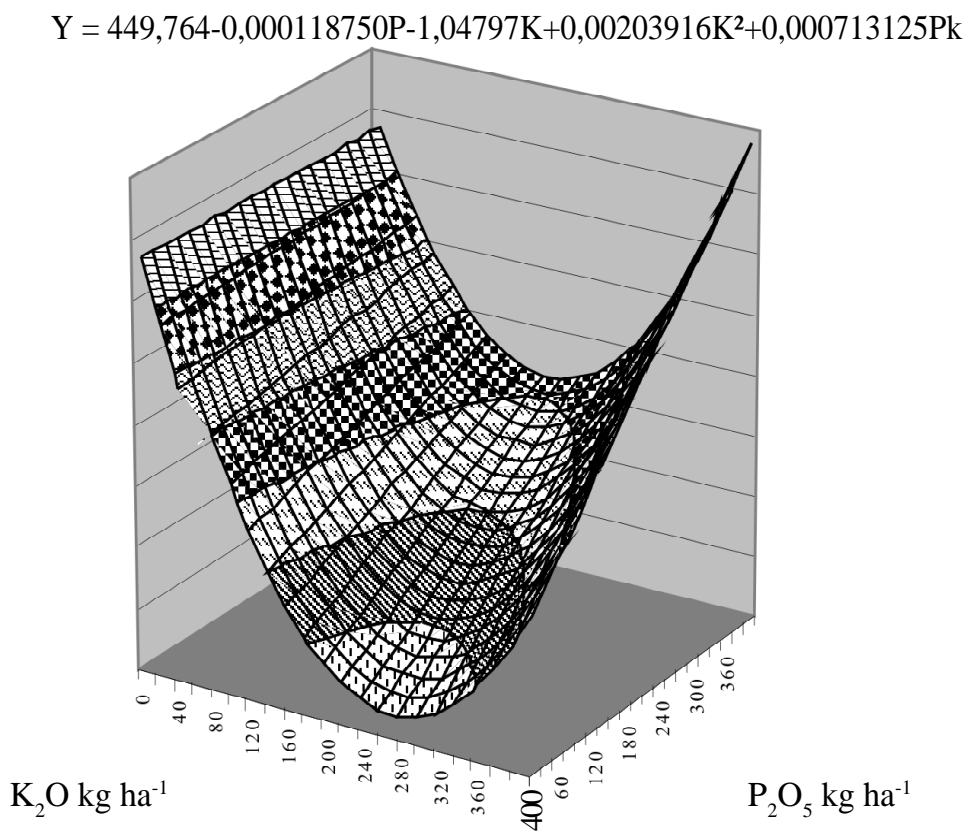

Figura 3 - Resposta da cultivar BR Roraima em número de panículas $\mathrm{m}^{-2}$ em resposta a diferentes níveis de $\mathrm{K}_{2} \mathrm{O}$ e $\mathrm{P}_{2} \mathrm{O}_{5}$ em solo de várzea em Roraima. 
potássio $\left(157,92 \mathrm{~kg} \mathrm{ha}^{-1}\right)$ é compatível com o alto nível de produtividade econômica $\left(7.501 \mathrm{~kg} \mathrm{ha}^{-1}\right)$ obtida já no primeiro ano de cultivo (Tabela 3 ).

Estes dados concordam com Santos et al. (1999) que obtiveram aumento de produtividade significativo $(19,5 \%)$ com o aumento de 35 para $70 \mathrm{~kg} \mathrm{ha}^{-1}$ de $\mathrm{K}_{2} \mathrm{O}$ com inundação continua e aplicação parcelada, atingindo a produtividade média de $6.269 \mathrm{~kg} \mathrm{ha}^{-1}$ com a segunda dose citada; Cabbau et al. (2004), estudando níveis críticos de potássio para solos de várzea, encontraram resposta positiva e linear a sua aplicação em casa de vegetação. No entanto Simonete et al. (2002) não encontraram resposta ao nutriente variando sua dose de 0 a $70 \mathrm{~kg} \mathrm{ha}^{-1} \mathrm{em}$ cultivo anterior ao do arroz, mesmo havendo teores mais elevados no solo com as maiores doses, concordando com dados obtidos por outros autores que demonstraram ser maior

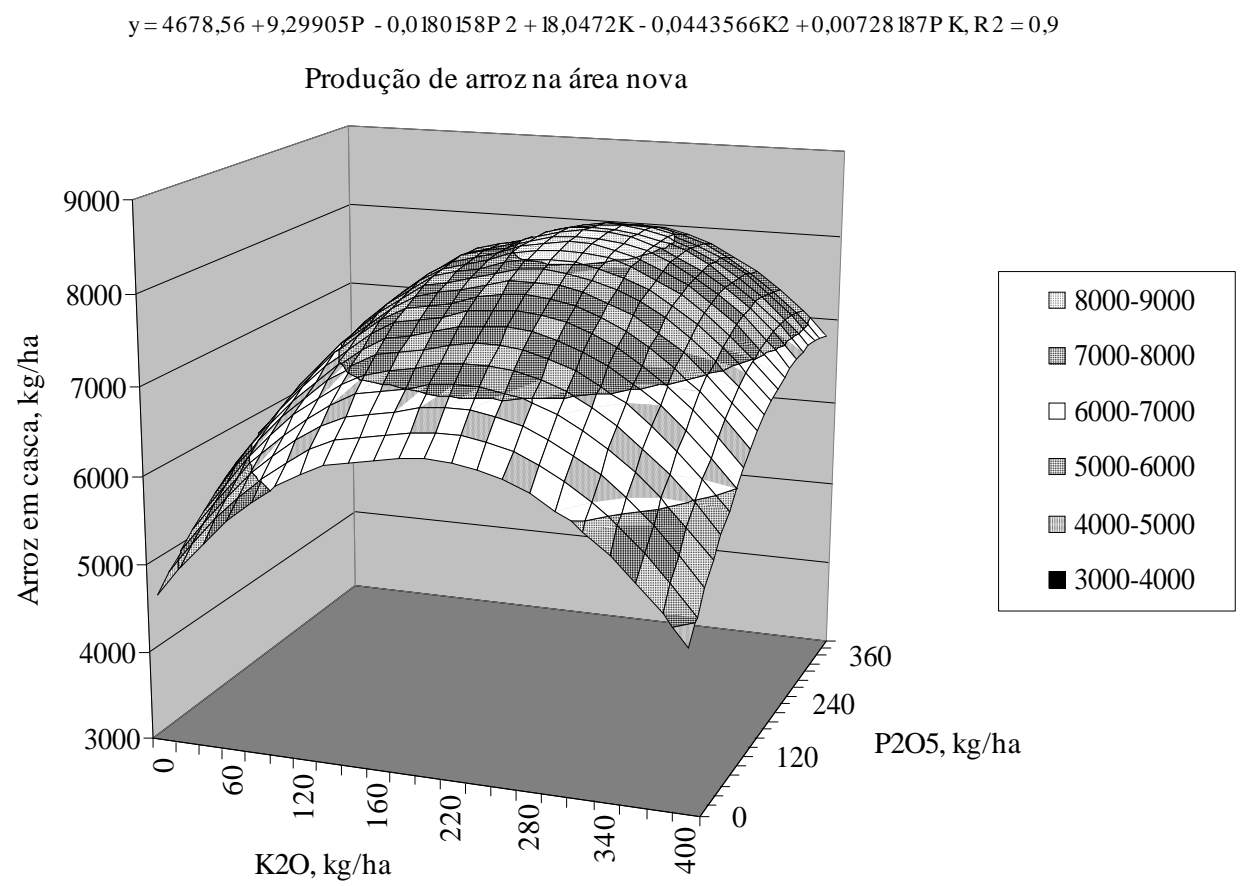

Figura 4 - Resposta de produtividade da cultivar BR Roraima a diferentes níveis de $\mathrm{K}_{2} \mathrm{O}_{2} \mathrm{P}_{2} \mathrm{O}_{5}$ em solo de várzea em Roraima.

Tabela 3 - Análise econômica da adubação com fósforo e potássio no experimento de arroz de várzea 'BR Roraima', em área de primeiro ano, safra 2007/08.

\begin{tabular}{|c|c|c|c|c|c|c|c|c|}
\hline \multicolumn{2}{|c|}{ Dose } & \multirow{2}{*}{ Produção } & \multirow{2}{*}{ Receita Bruta } & \multirow{2}{*}{ Custo total } & \multirow{2}{*}{$\begin{array}{l}\text { Receita } \\
\text { Líquida }\end{array}$} & \multirow{2}{*}{$\begin{array}{c}\text { Relação } \\
\text { benefício/custo }\end{array}$} & \multirow{2}{*}{\multicolumn{2}{|c|}{ Custo unitário }} \\
\hline $\mathrm{P}_{2} \mathrm{O}_{5}$ & $\mathrm{~K}_{2} \mathrm{O}$ & & & & & & & \\
\hline \multicolumn{2}{|c|}{-------- $\mathrm{kg} \mathrm{ha}^{-1}$} & ---------- & ----------------- & $\mathrm{R} \$ \mathrm{ha}^{-1}$ & ---------- & $\mathrm{R} \$ \mathrm{R}^{-1}$ & \multicolumn{2}{|c|}{$\mathrm{R} \$ \mathrm{~kg}^{-1}$} \\
\hline 0,00 & 0,00 & 4678,56 & $\mathrm{R} \$ 2.900,71$ & $\mathrm{R} \$ 3.000,00$ & $\mathrm{R} \$(99,29)$ & 0,97 & $\mathrm{R} \$$ & 0,6412 \\
\hline 134,32 & 0,00 & 5602,57 & $\mathrm{R} \$ 3.473,59$ & $\mathrm{R} \$ 3.467,43$ & $\mathrm{R} \$ \quad 6,16$ & 1,00 & $\mathrm{R} \$$ & 0,6189 \\
\hline 0,00 & 157,92 & 6422,38 & $\mathrm{R} \$ 3.981,87$ & $\mathrm{R} \$ 3.486,39$ & $\mathrm{R} \$ 495,48$ & 1,14 & $\mathrm{R} \$$ & 0,5429 \\
\hline 134,32 & 157,92 & 7500,98 & $\mathrm{R} \$ 4.650,60$ & $\mathrm{R} \$ 3.953,83$ & $\mathrm{R} \$ 696,78$ & 1,18 & $\mathrm{R} \$$ & 0,5271 \\
\hline 150,00 & 150,00 & 7541,10 & $\mathrm{R} \$ 4.675,48$ & $\mathrm{R} \$ 3.984,00$ & $\mathrm{R} \$ 691,48$ & 1,17 & $\mathrm{R} \$$ & 0,5283 \\
\hline 304,00 & 228,00 & 8154,59 & $\mathrm{R} \$ 5.055,84$ & $\mathrm{R} \$ 4.760,16$ & $\mathrm{R} \$ 295,68$ & 1,06 & $\mathrm{R} \$$ & 0,5837 \\
\hline
\end{tabular}

Obs.: Custo de produção médio de $\mathrm{R} \$ 3.000,00 \mathrm{ha}^{-1}$; custo do arroz em casca de $\mathrm{R} \$ 31,00 /$ saca de $50 \mathrm{~kg}$; custo do adubo: $\mathrm{P}_{2} \mathrm{O}_{5}-$ $\mathrm{R} \$ 3,48 \mathrm{~kg}^{-1} ; \mathrm{K}_{2} \mathrm{O}-\mathrm{R} \$ 3,08 \mathrm{~kg}^{-1}$. 
parte do potássio acumulado na parte aérea, influindo não significativamente na produtividade.

Os componentes de produção que se relacionaram com a produtividade foram a massa de mil grãos $(\mathrm{r}=0,4921 * *)$ e o número de grãos por panícula $(\mathrm{r}=0,7222 * *)$ (Tabela 4). Além desses dois componentes, a altura de planta se relacionou estreitamente com a produtividade $\left(\mathrm{r}=0,6854^{* *}\right)$.

$\mathrm{O}$ aumento da produtividade foi decorrente do crescimento da massa de mil grãos e, principalmente, do número de grãos cheios por panícula. $\mathrm{O}$ crescimento em altura obtido em resposta a aplicação dos tratamentos, especialmente de potássio (Figura 1c), possivelmente, reduziu o perfilhamento das plantas e, em consequência, o número de panícula $\mathrm{m}^{-2}(\mathrm{r}=-0,4438 * *)$. Porém, essa redução foi compensada pelo aumento no número de grãos por panícula $\left(\mathrm{r}=0,8008^{* *}\right)$. Assim, a adubação potássica aumentou o crescimento da planta, que se tornou mais robusta e suportou a presença de uma panícula maior, com maior número de grãos e com grãos mais pesados, compensando o menor número de panículas $\mathrm{m}^{-2}$. Esse efeito conjunto resultou nas maiores produtividades observadas.

Correlações positivas entre a altura de planta e a produtividade também foi verificado por Costa et al. (2000), estudando as características agronômicas da cultura principal do arroz e da soca para várias cultivares, encontraram correlação positiva e significativa de $0,58 * *$ para o cultivo principal e $0,42 *$ para a soca entre a produtividade e a altura das plantas. A importância do número de panícula $\mathrm{m}^{-2}$ sobre a formação da produtividade foi enfatizada por Fageria et al. (2000), que mostra correlação direta e positiva entre essas duas variáveis. Porém, neste trabalho, foi visto que nem sempre esta variável explica a produtividade, podendo esta ser mais explicada pelos outros componentes produção com correlação direta e mais significativa, como discutido anteriormente.

Tabela 4 - Coeficientes de correlação entre produtividade e os componentes de produção.

\begin{tabular}{|c|c|c|c|c|c|}
\hline Variável & 1 & 2 & 3 & 4 & 5 \\
\hline 1 Produtividade & & & & & \\
\hline 2 Massa de mil grãos & $0,4921 * *$ & & & & \\
\hline $3 \mathrm{~N}^{\mathrm{o}}$ de panículas $\mathrm{m}^{2}$ & $-0,0256^{\mathrm{ns}}$ & $-0,099^{\mathrm{ns}}$ & & & \\
\hline 4 Esterilidade & $-0,1628^{\mathrm{ns}}$ & $-0,8788 * *$ & $-0,1099^{\mathrm{ns}}$ & & \\
\hline 5 Altura & $0,6854 * *$ & $0,5444 * *$ & $-0,4438 *$ & $-0,1866^{\mathrm{ns}}$ & \\
\hline $6 \mathrm{~N}^{\mathrm{o}}$ de grãos cheios/panícula & $0,7228 * *$ & $0,5259 * *$ & $-0,4859 * *$ & $-0,0756^{\mathrm{ns}}$ & $0,8008 * *$ \\
\hline
\end{tabular}

$*,{ }^{*},{ }^{\text {ns }}=$ significativo a $5 \%$ e $1 \%$ probabilidade e não significativo, respectivamente. 


\section{CONCLUSÕES}

$\mathrm{O}$ uso de $134 \mathrm{~kg} \mathrm{ha}^{-1}$ de $\mathrm{P}_{2} \mathrm{O}_{5}$ e $157 \mathrm{~kg} \mathrm{ha}^{-1}$ de $\mathrm{K}_{2} \mathrm{O}$ proporciona a máxima produtividade econômica $\left(7.501 \mathrm{~kg} \mathrm{ha}^{-1}\right.$ de grãos de arroz em casca) na cultivar BR Roraima, em várzeas no primeiro ano de cultivo no estado de Roraima.

$\mathrm{O}$ uso das doses recomendadas permite a obtenção de receita líquida de $\mathrm{R} \$ 697 \mathrm{ha}^{-1}$, com relação benefício/ custo de 1,18 e obtenção de custo unitário de $\mathrm{R} \$ 0,5271$ por kg de arroz em casca, já no primeiro ano de cultivo.

Há resposta em produtividade física de arroz em casca até $8.154 \mathrm{~kg} \mathrm{ha}^{-1}$, com o uso de até $304 \mathrm{~kg} \mathrm{ha}^{-1} \mathrm{de}$ $\mathrm{P}_{2} \mathrm{O}_{5}$ e $228 \mathrm{~kg} \mathrm{ha}^{-1}$ de $\mathrm{K}_{2} \mathrm{O}$.

A produtividade está relacionada com o aumento no número de grãos por panícula, a altura de planta e com a massa de mil grãos.

\section{REFERÊNCIAS BIBLIOGRÁFICAS}

BANCO DA AMAZÔNIA. Custo para $\mathbf{1 , 0}$ ha de arroz irrigado. Boa Vista, 2006.

CABBAU, A.R. et al. Resposta e níveis críticos de Potássio para o arroz cultivado em solos de várzea inundados. Ciência e Agrotecnologia, Lavras, v.28, n.1, p.75-86, jan./fev. 2004.

COSTA, E.G. de C.; SANTOS, A.B.; ZIMMERMANN, F.J.P. Características agronômicas da cultura principal e da soca de arroz irrigado. Disponível em: $<\mathrm{http}: / /$

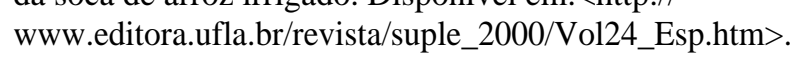
Acesso em: 25 fev. 2009.

DIEL, M. et al. Nutrientes na água para irrigação de arroz na região sul do Rio Grande do Sul, Brasil. Ciência

Rural, Santa Maria, v.37, p.102-109, jan./fev. 2007.

FAGERIA, N.K.; SANTOS, A.B.; ZIMMERMANN, F.J.P. Resposta do arroz irrigado à adubação residual e aos níveis de adubação em solo de várzea. Revista Brasileira de Engenharia Agrícola e Ambiental, Campina Grande, v.4, n.2, p.177-182, 2000.

FAGERIA, N.K.; ZIMMERMMANN, F.J.P. Resposta de arroz irrigado a adubação em solos de várzea. Pesquisa Agropecuária Brasileira, Brasília, v.31, n.6, p.463-466, jun. 1996.
FECOMÉRCIO. Revista Somos, Boa Vista, n.10, set. 2008.

GENRO JUNIOR, S.A.; MARCOLIN, E.;

ANGHINONI, I. Eficácia das recomendações de adubação para diferentes expectativas de produtividade de arroz irrigado por inundação.

Revista Brasileira de Ciência do Solo, Viçosa, v.34, p.1667-1675, 2010.

HERNANDES, A. et al. Doses, fontes e épocas de aplicação de nitrogênio em cultivares de arroz. Ciência e Agrotecnologia, Lavras, v. 34, n. 2, p. 307 a 312, mar./abr., 2010.

MACHADO, S.L.O. et al. Consumo de água e perdas de nutrientes e de sedimentos na água de drenagem inicial do arroz irrigado. Ciência Rural, Santa Maria, v.36, n.1, jan./fev. 2006.

MARIANO, I.O.S. et al. Efeito residual da adubação fosfatada e da calagem e níveis críticos de fósforo em plantas de arroz cultivadas em solos inundados. Ciência e Agrotecnologia, Lavras, v.26, n.4, p.731-740, jul./ago. 2002.

ROTILI, E.A. et al. Eficiência no uso de fósforo de variedades de arroz cultivadas em solos de várzea irrigada. Revista Ceres, Viçosa, v.57, n.3, p.415-420, maio/jun. 2010.

SANTOS, A.B. et al. Manejo de água e de fertilizante potássico na cultura de arroz irrigado. Pesquisa Agropecuária Brasileira, Brasília, v.34, n.4, p.565-573, abr. 1999.

SIMONETE, M.A. et al. Efeito residual da adubação potássica do azevém sobre o arroz subsequente em plantio direto. Revista Brasileira de Ciência do Solo, Viçosa, v.26, p.721-727, 2002.

WEBER, L. et al. Cultivares de arroz irrigado e nutrientes na água de drenagem em diferentes sistemas de cultivos. Ciência Rural, Santa Maria, v.33, n.1, p.2733, 2003. 